\title{
Could a randomised trial answer the controversy relating to elective caesarean section? National survey of consultant obstetricians and heads of midwifery
}

Tina Lavender, Carol Kingdon, Anna Hart, Gill Gyte, Mark Gabbay, James P Neilson

Department of

Midwifery Studies,

University of

Central Lancashire,

Preston PR1 2HE

Tina Lavender

professor of midwifery

and women's healt

Carol Kingdon

research fellow

Lancashire School

of Health and Post

Graduate Medicine,

University of

Central Lancashire

Anna Hart

principal lecturer

Cochrane

Pregnancy and

Childbirth Group

University of

Liverpool,

Liverpool Women'

Hospital, Liverpool

L8 7 SS

Gill Gyte

consumer panel

coordinator

University of

Liverpool,

Liverpool L69 3GB

Mark Gabbay

senior lecturer in

general practice

continued over

BMJ 2005;331:490-1
International concerns about rising rates of caesarean section are counterbalanced by arguments that planned caesarean section without specific clinical indication (such as breech presentation or HIV infection) falls within legitimate maternal choice. ${ }^{1}$ Professional opinion is divided. To perform a caesarean section without clinical reason is seen as ethical, in response to maternal request, by the American College of Obstetricians and Gynecologists; is enshrined in law in Italy; but is viewed as unethical by the International Federation of Gynecology and Obstetrics. The National Institute for Health and Clinical Excellence recommends that a second opinion should be offered. ${ }^{2}$ A well designed, randomised controlled trial of planned caesarean section compared with planned vaginal birth could provide important evidence. ${ }^{3}$

\section{Participants, methods, and results}

We aimed to survey all consultant obstetricians and heads of midwifery (gatekeepers to such a trial) practising in England between January 2003 and May 2004. We explored their views of women's requests for caesarean section without clinical indication and of a possible randomised controlled trial in a postal survey. We used semistructured questionnaires with closed questions followed by free text spaces to provide supporting rationale. Comparisons were made between professionals and according to parental status, sex, and type of unit where they worked. We used $\chi^{2}$ tests to compare the proportion of respondents saying "yes" to each question. Two of the authors (TL, CK) manually analysed qualitative responses.

Altogether 660/924 (71\%) eligible obstetricians and 123/169 (73\%) midwives responded (table). Almost half of the obstetricians and a quarter of midwives believed that a woman should choose her method of delivery. A minority thought a trial was feasible, ethical, or desirable. Female obstetricians were less likely to support a trial than male ones. Whether or not the obstetrician and midwife had children did not influence their responses; nor did the type of unit in which the professionals worked.

A full description of qualitative findings will be presented elsewhere. Most respondents providing qualitative commentary wished they had the results of a randomised controlled trial. Obstetricians and midwives who were opposed to a trial offered similar reasons, motivated by unease with routine caesarean section (interference with nature, maternal morbidity, and impact on organisational resources and professional roles). Marked differences occurred in the responses of health professionals who supported a trial: obstetricians mainly believed that lack of evidence prevented women making informed choices, whereas midwives were confident that a trial would prove that vaginal birth was superior.

This article was first posted on bmi.com on 22 August 2005: http://bmj.com/cgi/doi/10.1136/bmj.38560.572639.3A

Findings of survey. Values are numbers (with rounded percentages) of participants unless otherwise indicated

\begin{tabular}{|c|c|c|c|c|c|c|c|}
\hline \multirow[b]{2}{*}{ Survey question } & \multirow[b]{2}{*}{ Answer } & \multicolumn{4}{|c|}{ Consultant obstetricians } & \multirow[b]{2}{*}{$\begin{array}{l}\text { Heads of midwifery } \\
\qquad(n=123)\end{array}$} & \multirow[b]{2}{*}{$\begin{array}{c}\chi^{2} \text { test comparing } \\
\text { professional groups } \ddagger\end{array}$} \\
\hline & & $\begin{array}{c}\text { All } \\
(\mathrm{n}=660)\end{array}$ & $\begin{array}{c}\text { Male } \\
(\mathrm{n}=468)\end{array}$ & $\begin{array}{c}\text { Female } \\
(\mathrm{n}=188)^{*}\end{array}$ & $\begin{array}{l}\chi^{2} \text { test comparing } \\
\text { sexest }\end{array}$ & & \\
\hline \multirow{3}{*}{$\begin{array}{l}\text { Do you believe that primigravid women (in the } \\
\text { absence of clinical indications) should choose } \\
\text { their method of delivery? }\end{array}$} & Yes & $321(49)$ & $254(54)$ & $67(36)$ & \multirow[t]{3}{*}{$P<0.001$} & $33(27)$ & \multirow[t]{3}{*}{$P<0.001$} \\
\hline & No & $325(49)$ & 207 (44) & $117(62)$ & & $85(69)$ & \\
\hline & Missing & $14(2)$ & $7(1)$ & $4(2)$ & & $5(4)$ & \\
\hline \multirow{3}{*}{$\begin{array}{l}\text { Is a randomised controlled trial of elective } \\
\text { caesarean section } v \text { vaginal birth ethical? }\end{array}$} & Yes & $246(37)$ & $189(40)$ & $57(30)$ & \multirow[t]{3}{*}{$\mathrm{P}=0.013$} & $26(21)$ & \multirow[t]{3}{*}{$P<0.001$} \\
\hline & No & $367(56)$ & $252(54)$ & $114(61)$ & & $86(70)$ & \\
\hline & Missing & $47(7)$ & $27(6)$ & $17(9)$ & & $11(9)$ & \\
\hline \multirow{3}{*}{$\begin{array}{l}\text { Is a randomised controlled trial of elective } \\
\text { caesarean section } v \text { vaginal birth feasible? }\end{array}$} & Yes & $159(24)$ & $128 \quad(27)$ & $31(17)$ & \multirow[t]{3}{*}{$P=0.001$} & $35(29)$ & \multirow[t]{3}{*}{$P=0.32$} \\
\hline & No & $434(66)$ & $297(64)$ & $136(73)$ & & $72(59)$ & \\
\hline & Missing & $67(10)$ & $43(9)$ & $20(11)$ & & $16(13)$ & \\
\hline \multirow{3}{*}{$\begin{array}{l}\text { Is a randomised controlled trial of elective } \\
\text { caesarean section } v \text { vaginal birth desirable? }\end{array}$} & Yes & $294(45)$ & $218(47)$ & $76(41)$ & \multirow[t]{3}{*}{$P=0.15$} & $39(32)$ & \multirow[t]{3}{*}{$P=0.005$} \\
\hline & No & 318 (48) & $223(48)$ & $94(50)$ & & $73(59)$ & \\
\hline & Missing & $48(7)$ & $27(6)$ & $17(9)$ & & $11(9)$ & \\
\hline \multirow{3}{*}{$\begin{array}{l}\text { Would you recruit women to a randomised } \\
\text { controlled trial of caesarean section } v \text { vaginal } \\
\text { delivery? }\end{array}$} & Yes & $247(37)$ & $186(40)$ & $61(32)$ & \multirow[t]{3}{*}{$P=0.073$} & $21(17)$ & \multirow[t]{3}{*}{$P<0.001$} \\
\hline & No & $376(57)$ & $259(55)$ & $116(62)$ & & $89(72)$ & \\
\hline & Missing & $37(6)$ & $23(5)$ & $11(6)$ & & $13(11)$ & \\
\hline \multirow{4}{*}{$\begin{array}{l}\text { Would you consider an elective caesarean } \\
\text { section for yourself (or partner)? }\end{array}$} & Yes & $216(33)$ & $180(39)$ & $35(19)$ & \multirow[t]{4}{*}{$(P<0.001) \S$} & $9(7)$ & \multirow[t]{4}{*}{$(\mathrm{P}<0.001) \S$} \\
\hline & No & $316(48)$ & $189(40)$ & $127 \quad(68)$ & & $100(81)$ & \\
\hline & $\mathrm{N} / \mathrm{A}$ & 98 (15) & $80(17)$ & $18(10)$ & & 0 & \\
\hline & Missing & $30(5)$ & 19 (4) & 8 (4) & & 14 (11) & \\
\hline
\end{tabular}

${ }^{\star}$ Sex was unknown for four.

†P values for $\chi^{2}$ test comparing proportions of "yes" replies between sexes for obstetricians.

†P values for $\chi^{2}$ test comparing proportions of "yes" replies between professional groups.

$\S$ Not applicable. Values have been omitted from the analysis. 


\section{What is already known on this topic}

Caesarean section, in the absence of clear clinical indication, is one of the most contentious issues in modern obstetrics, fuelling debates about the possible need for a randomised trial of delivery methods

Evidence about the extent to which obstetricians support women's requests for caesarean section is conflicting, and views on the need for a trial of planned caesarean section versus planned vaginal birth have not been reported

\section{What this study adds}

A minority of consultant obstetricians and heads of midwifery would support a randomised trial of planned caesarean section compared with planned vaginal birth

\section{Comment}

Our quantitative findings indicate that a minority of professionals would recruit to a trial comparing planned caesarean section with planned vaginal birth. However, the qualitative finding-that midwives who favoured a trial did so because of their confidence in the benefits of vaginal birth-adds complexity because it negates the necessary individual professional equipoise. ${ }^{4}$ We explored the opinions of senior obstetricians and midwives simultaneously and nationally, and we identified views about a possible randomised trial. To gain unbiased views, we deliberately did not present participants with a protocol, rather than give the impression that a trial was planned. We also believe that evidence about benefits and risks is insufficient to develop a protocol.

If caesarean birth were shown to be as safe as normal birth in a non-inferiority trial, the NHS would have to consider whether it would be willing to offer such a choice, given the huge resource implications. ${ }^{2}$ If the cost makes offering choice to all women unfeasible then carrying out a trial would be unethical. The ethical, moral, and practical challenges to a trial are considerable and would require involvement of women and society at large.

The authors acknowledge the support of Ruth Cattrell, research midwife, all of the heads of midwifery, and consultant obstetricians who participated.

Contributors: TL, CK, GG, MG, and JPN designed the study. TL, $\mathrm{CK}$, and $\mathrm{AH}$ analysed the data. TL, CK, and AH wrote the paper. TL, CK, AH, GG, MG, and JPN reviewed and amended drafts of the paper. All authors contributed critical comments to the paper. TL is the principal investigator of the survey and principal guarantor of the paper.

Funding: University of Central Lancashire, University of Liverpool and Liverpool Women's Hospital NHS Trust.

Competing interests: None declared.

Ethical approval: Liverpool Research Ethics Committee (twice; reference 01/008-08/03/2001, reference 01/008-11/03/2003).

1 Minkoff H, Chervenak F. Elective primary cesarean delivery. N EnglJ Med 2003;348:946-50.

National Collaborating Centre for Women's and Children's Health. Caesarean section clinical guideline. London: RCOG Press, 2004.

3 Ecker JL. Once a pregnancy always a cesarean? Rationale and feasibility of a randomized controlled trial. Am J Obstet Gynecol 2004;190:314-8.

Weijer C, Shapiro SH, Glass KC, Enkin MW. Clinical equipoise and not the uncertainty principle is the moral underpinning of the randomised the uncertainty principle is the moral underpinning of the randomised
controlled trial. BMJ 2000;321:756-8.

(Accepted 6July 2005)

doi $10.1136 / \mathrm{bmj} .38560 .572639 .3 \mathrm{~A}$
School of

Reproductive and Developmental Medicine,

University of

Liverpool,

Liverpool Women's

Hospital, Liverpool

L8 7SS

James P Neilson

professor of obstetrics

and gynaecology

Correspondence to:

T Lavender

tinalav@yahoo.co.uk
Decreased mortality and reduced disability are well recognised short term benefits of care in a stroke unit. ${ }^{1}$ Early organised management improves survival up to five years after stroke. ${ }^{2}$ Only one study has examined the effects of care in a stroke unit for longer than five years, ${ }^{3}$ and it showed that treatment in a combined acute and rehabilitation stroke unit in Norway conferred benefit even 10 years after stroke. We aimed to examine whether the benefits of a non-acute stroke rehabilitation unit persist for 10 years after stroke. This study was a continuation of the five year follow-up by Lincoln and colleagues. ${ }^{2}$

\section{Participants, methods, and results}

We identified participants who had been randomly allocated to receive treatment in a non-acute stroke unit or on conventional wards (general medical wards or wards for the elderly) as part of an earlier trial. ${ }^{4}$ Ten years after that randomisation, we traced them on hospital and general practice databases. We asked survivors to consent to follow-up with a postal questionnaire. Participants needing help to complete the questionnaire were visited by researchers who were blind to original group allocation and to five year results for individuals.

We recorded place of residence. We used the Barthel index to measure independence in personal activities of daily living ${ }^{5}$ : we classified participants as disabled (0-17) or independent (18-20). We obtained age, sex, and date of stroke from previous records. We compared survival for participants in the two groups (stroke unit and conventional ward) over 10 years using Kaplan-Meier survival curves.

In the original study, 176 participants were randomly allocated to receive treatment in a stroke unit and 139 to receive treatment on a conventional

This article was posted on bmj.com on 10 August 2005: http://bmj.com/ cgi/doi/10.1136/bmj.38537.679479.E0
Division of Ageing and Rehabilitation, Queen's Medical Centre, Nottingham NG7 2UH

Avril E R

Drummond research occupational therapist

Derbyshire Royal Infirmary, Derby DE1 2QY

Ben Pearson consultant physician in emergency medicine continued over

BMJ 2005;331:491-2 